\title{
Pastas de Rhodomonas salina (Cryptophyta) como alimento para Brachionus plicatilis (Rotifera)
}

\author{
Miguel Guevara ${ }^{1,2^{*}}$, Leandro Bastardo ${ }^{2}$, Roraysi Cortez ${ }^{2}$, Bertha Arredondo-Vega ${ }^{3}$, Lolymar \\ Romero ${ }^{4}$ \& Patricia Gómez ${ }^{1}$ \\ 1. Departamento de Botánica, Facultad de Ciencias Naturales y Oceanográficas, Centro de Biotecnología, Universidad \\ de Concepción, Casilla 160-C, Concepción, Chile; miguevara2003@yahoo.es, pgomez@udec.cl \\ 2. Instituto Oceanográfico de Venezuela, Universidad de Oriente, Apartado 6101, Cumaná, Venezuela; \\ 1.bastardo@hotmail.com,roraysi@yahoo.com \\ 3. Centro de Investigaciones Biológicas del Noroeste, S. C. (CIBNOR), Baja California, México; kitty04@cibnor.mx \\ Instituto Universitario de Tecnología, Apartado 6101, Cumaná, Venezuela; lolyrome@yahoo.com \\ * Correspondencia
}

Recibido 14-XII-2010. Corregido 02-III-2011. Aceptado 05-IV-2011.

\begin{abstract}
Rhodomonas salina (Cryptophyta) pastes as feed for Brachionus plicatilis (Rotifera). Rotifers are an important live feed for first feeding larvae of many fish species. The use of concentrated algae cells in the mass culture of the rotifer Brachionus plicatilis (Brachionidae) has opened new horizons for research on this organism. Pastes of Rhodomonas salina (Pyrenomonadaceae) obtained either by centrifugation or flocculation with chitosan were preserved, with or without vitamin $\mathrm{C}$, at $-20^{\circ} \mathrm{C}$ for four weeks and were evaluated biochemically (proteins, lipids, pigments and fatty acids contents) and subsequently, were used to feed the rotifer Brachionus plicatilis at a ratio of $25 \mathrm{mg} / \mathrm{L} /$ day. Four different microalgae pastes were prepared: (1) centrifuged and preserved with vitamin $\mathrm{C}(\mathrm{CV}),(2)$ centrifuged and preserved without vitamin $\mathrm{C}(\mathrm{C})$, (3) flocculated and with vitamin $\mathrm{C}(\mathrm{FV})$ and (4) flocculated without vitamin $\mathrm{C}(\mathrm{F})$. All treatments showed similar contents of proteins and total lipids with respect to control culture (a fresh culture of $R$. salina), with mean values of $40.0 \pm 2.32 \%$ and $12.0 \pm 1.45 \%$, respectively. The pheophytin $a$ /chlorophyll $a$ ratio, a general indicator of the chemical status of microalgal concentrates, was similar $(0.09-0.11)$ between centrifuged pastes and control culture, but was found to be higher in flocculated pastes (1.28-1.48). The fatty acid profile varied with respect to the control culture, mainly in the proportion of the essential polyunsaturated fatty acids (PUFAs): eicosapentaenoic acid (EPA) and docosahexaenoic acid (DHA). Total PUFAs, EPA and DHA contents were statistically similar between centrifuged pastes and control culture (PUFAs: 47\%, EPA: 4\% and DHA: 4.7\%), whereas values obtained for flocculated pastes were significantly lower. The rotifers grew equally well when fed with centrifuged pastes or control culture (maximum density: 320rotifers $/ \mathrm{mL}$; instantaneous growth rate: 0.23rotifers/ day, fecundity: $1.49 \mathrm{eggs} / \mathrm{female}$ and productivity: $43 \times 10^{3}$ rotifers/L/day. No significant effect of vitamin $\mathrm{C}$ was found when used as a paste preservative. We concluded that centrifugation is an effective harvesting method, and that freezing to $-20^{\circ} \mathrm{C}$ for four weeks (no vitamin added), may help maintain the nutritional quality of $R$. salina paste, similar to fresh microalgae and can be offered to Brachionus plicatilis. Rev. Biol. Trop. 59 (4): 1503-1515. Epub 2011 December 01.
\end{abstract}

Key words: microalgae paste, aquaculture, Rhodomonas salina, flocculation, rotifers.

La producción de microalgas en las salas de cría tiene como objetivo proveer de alimento vivo, de excelente calidad nutricional, a especies animales en cultivo, especialmente larvas y juveniles de moluscos bivalvos y camarones peneidos (Brown \& Robert 2002). Esta actividad presenta un elevado costo de producción, el cual puede variar entre 50 y $200 \$$ / $\mathrm{kg}$ de biomasa seca de microalga, lo que puede representar entre el 20 y el $50 \%$ de los costos de operación de una sala de cría (Borowitzka 1997). Una alternativa a este problema es el uso 
de biomasa microalgal preservada en forma de pastas, ya que ésta podría reducir los costos de producción y, además, disminuir la dependencia del alimento vivo en los periodos donde las variaciones estacionales limitan su producción (Heasman et al. 2000).

La centrifugación es el método más usado para obtener concentrados microalgales; mientras que la floculación, un método ampliamente usado en la industria para remover sólidos en suspensión, también ha sido exitosamente aplicado a la cosecha de biomasa microalgal (Molina-Grima et al. 2003). Los concentrados de microalgas producidos por centrifugación o floculación y mantenidos refrigerados entre 2 y $4^{\circ} \mathrm{C}$ por una a ocho semanas, se han usado exitosamente en la alimentación de larvas y juveniles de bivalvos (Bonaldo et al. 2005). Nell \& O'Connor (1991) encontraron que las larvas de Saccostrea glomerata mostraron un crecimiento equivalente al ser alimentadas con Pavlova lutheri e Isochrysis galbana, tanto en forma de dieta viva o como pasta. Resultados similares fueron obtenidos por Brown \& Robert (2002) en larvas y jóvenes de Crassostrea gigas, alimentadas con pastas floculadas de Chaetoceros calcitrans. A pesar de que las pastas preservadas de microalgas constituyen un alimento de bajo costo (Conceição et al. 2010), fácil obtención (Bonaldo et al. 2005) y transporte, hay que tener en consideración que la preservación en el tiempo de su calidad nutricional es específica-especie, dadas las variadas características morfo-estructurales de la pared celular de las microalgas (Ponis et al. 2008). Es así, por ejemplo, como los concentrados unialgales de Chaetoceros calcitrans, Skeletonema costatum y Tetraselmis spp. que se mantienen bajo refrigeración conservan su composición bioquímica hasta por un periodo de dos meses (Heasman et al. 2000); mientras que la biomasa de Isochrysis sp. (TISO) y Pavlova lutheri, se deteriora con mayor facilidad (Molina-Grima et al. 1994, McCausland et al. 1999). Entre los métodos utilizados para preservar la calidad nutricional de las pastas microalgales están: la aplicación de antioxidantes (Molina-Grima et al. 1994, Heasman et al. 2000, Tzovenis et al. 2004), control de luz (Montaini et al. 1995, Chini Zittelli et al. 2003), liofilización (Albentosa et al. 1997), temperatura (McCausland et al. 1999), aireación (Ponis et al. 2008), congelación (Lubzens et al. 1995) y refrigeración (Robert et al. 2001, Nunes et al. 2009).

Las criptófitas han sido poco utilizadas para producir concentrados algales, a pesar de su excelente calidad nutricional y facilidad de cultivo (Renaud et al. 2002, Bermúdez et al. 2004). Rhodomonas salina (Wislouch) Hill \& Wetherbee (1989) es la criptófita que más se ha utilizado en acuicultura debido, principalmente, a su alto contenido de proteínas, lípidos y ácidos grasos poliinsaturados (Fernández et al. 1989, Zhukova \& Aizdaicher 1995, Dunstan et al. 2005). Su valor nutricional explica su capacidad para incrementar la tasa de supervivencia del pectínido Pecten maximus (Tremblay et al. 2007) y la tasa de crecimiento instantánea de juveniles de Crassostrea gigas (MCCausland et al. 1999). Por eso uno de los objetivos de este estudio fue evaluar la composición bioquímica de pastas obtenidas a partir de una cepa de Rhodomonas salina, mediante el uso de distintos métodos de cosecha y preservación del concentrado microalgal.

El rotífero Brachionus plicatilis (Müller) es usado ampliamente en acuicultura como vehículo para proporcionar nutrientes esenciales a especies animales en cultivo. Entre sus características destacan su tamaño microscópico (130-300 $\mu \mathrm{m})$, movimiento lento en el agua, fácil y económica alimentación con diferentes especies de fitoplancton y/o levadura, a parte de su tasa alta de reproducción (James et al. 1983). El cultivo de B. plicatilis data desde 1960 y, a partir de esa fecha, se ha venido empleando en la larvicultura de diversas especies de peces (Theilacker \& McMaster 1971, Opstad et al. 1985, Lubzens et al. 1989, Cavalin \& Weirich 2009) y crustáceos (Liao et al. 1983, Alvarez \& Ewald 1990).

Brachionus plicatilis ha sido alimentado exitosamente con diferentes microalgas, ya sea en forma fresca o como pasta congelada (Lubzens et al. 1995), polvo seco (Robert \& Trintignac 1997) y polvo liofilizado (Yúfera 
\& Navarro 1995, Navarro \& Sarasquete 1998); siendo las pastas congeladas una de las mejores fuentes de nutrientes para estos organismos (Lubzens et al.1995, Gallagher et al. 2001). El uso de pastas de $R$. salina para la alimentación del rotífero Brachionus plicatilis no está documentado, por lo cual esta investigación planteó la evaluación de este tipo pasta como alimento de este importante microinvertebrado.

\section{MATERIALES Y MÉTODOS}

Cepa de microalga y del rotífero: La cepa CS174 de Rhodomonas salina (Wislouch) Hill \& Wetherbee (1989) fue obtenida del Cepario CSIRO Algal Culture Collection, CSIRO Division of Marine Research, Hobart, Tasmania. La cepa de Brachionus plicatilis fue aislada de las salinas de Araya, Venezuela (10³0'-1040"

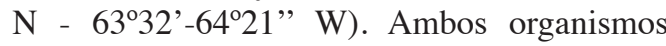
están depositados en la colección de cultivos planctónicos del Laboratorio de Acuicultura, extensión Plancton del Departamento de Biología Pesquera, del Instituto Oceanográfico de Venezuela, Universidad de Oriente.

Condiciones del cultivo de la microalga: Un cultivo de $R$. salina en fase de crecimiento exponencial, aclimatado durante tres generaciones $(\mathrm{K}=0.9 \mathrm{div} / \mathrm{dí}$ ) a luz continua ( $100 \mu \mathrm{mol} / \mathrm{m}^{2} / \mathrm{s}$ de irradianza), $29 \pm 1^{\circ} \mathrm{C}$ y $\mathrm{pH}$ entre 7.5-8.5 se usó para inocular 13L de medio fresco contenidos en botellones de vidrio de $15 \mathrm{~L}$, provistos de aireación constante $(200 \mathrm{~mL} /$ min). Estos nuevos cultivos se realizaron por cuadruplicado con una densidad inicial de $1 \times 10^{5} \mathrm{cel} / \mathrm{mL}$, en medio $\mathrm{f} / 2$ (Guillard 1975) con una concentración de nitrato y fosfato de $3.5 \mathrm{mM}$ y $0.018 \mathrm{mM}$, respectivamente, utilizando agua de mar (37UPS) filtrada y esterilizada en autoclave $\left(15 \mathrm{psi} / 120^{\circ} \mathrm{C} / 15 \mathrm{~min}\right)$.

\section{Producción de pastas algales de Rhodo-} monas salina: Cuando los cultivos alcanzaron la fase de crecimiento exponencial tardía (6to día), se procedió a realizar la cosecha total, para lo cual se evaluaron dos métodos: (a).Centrifugación: consistió en centrifugar 6L de cultivo, de cada réplica, a 3 000 rpm $/ 5 \mathrm{~min}$, usando tubos cónicos de $15 \mathrm{~mL}$ de capacidad. (b).- Floculación: se basó en agregar al cultivo (6L de cada réplica) una solución de quitosano en ácido acético $(7.5 \mathrm{~g}$ de quitosano $/ 500 \mathrm{~mL}$ de ácido acético al 20\%), al cual se le subió previamente el $\mathrm{pH}$ hasta $10 \mathrm{con} \mathrm{NaOH} 1 \mathrm{~mol} / \mathrm{L}$. La adición de la solución de quitosano fue hasta que el pH se estabilizó entre 7 y 8 . A continuación se agitó y dejó en reposo para propiciar la floculación (Morales et al. 1985).

Las pastas algales (obtenidas por centrifugación y floculación) fueron divididas en dos partes cada una y a una de las partes se le agregó $0.1 \% \mathrm{~m} / \mathrm{m}$ de vitamina $\mathrm{C}$ (ácido ascórbico) con la finalidad de evaluar su utilidad como antioxidante (Nunes et al. 2009). Posteriormente, todas las pastas fueron almacenadas durante cuatro semanas a $-20^{\circ} \mathrm{C}$ en oscuridad. De esta forma, quedaron constituidas cuatro tipos de pastas algales: (1) centrifugada y con vitamina $\mathrm{C}(\mathrm{CV}),(2)$ centrifugada y sin vitamina $\mathrm{C}(\mathrm{C})$, (3) floculada y con vitamina C (FV) y (4) floculada y sin adición de vitamina $\mathrm{C}(\mathrm{F})$.

Después de cuatro semanas de almacenamiento, se pesó $1 \mathrm{~g}$ de cada pasta microalgal y se resuspendió en $49 \mathrm{~mL}$ de agua de mar filtrada y esterilizada. A partir de esta resuspensión se determinó la concentración de proteínas totales (Lowry et al. 1951), lípidos totales (Marsh \& Weinstein 1966), ácidos grasos (Sato \& Murata 1988), clorofila $a$, feofitina $a$ y relación feofitina $a$ /clorofila $a$ (Lorenzen 1967). Los cultivos frescos de $R$. salina, se realizaron por cuadruplicado en similares condiciones, fueron analizados bioquímicamente y se usaron como controles.

Ensayos de alimentación del rotífero $B$. plicatilis con pastas algales: Los cultivos de B. plicatilis se realizaron, por cuadruplicado, en matraces de $500 \mathrm{ml}$ de capacidad con $250 \mathrm{ml}$ de agua de mar (37UPS) filtrada a través de una batería de filtros: $10 ; 5 ; 1 ; 0.1 \mu \mathrm{m}$ y esterilizada mediante tratamiento con luz UV. Los cultivos se iniciaron con una densidad de 100rotíferos/ $\mathrm{mL}$ y se mantuvieron con aireación continua $(50 \mathrm{~mL} / \mathrm{min})$. Diariamente, se les proporcionó, 
por separado, $25 \mathrm{mg} / \mathrm{L}$ de cada pasta de $R$. sali$n a$, previamente resuspendidas en agua de mar (Navarro \& Yúfera (1998). Paralelamente, en similares condiciones, se realizaron cultivos de B. plicatilis y se alimentaron con cultivos frescos de Rhodomonas salina (ración equivalente a $25 \mathrm{mg} / \mathrm{L} /$ día).

Diariamente, se determinó la densidad de rotíferos. Cuando los cultivos mostraron sus mayores valores de densidad poblacional se procedió a calcular la tasa instantánea de crecimiento, la fecundidad (número de huevos/hembra) y productividad (rotíferos/L/día) según Navarro \& Yúfera (1998).

Los resultados de las evaluaciones bioquímicas de las pastas microalgales, así como los datos de crecimiento, productividad y fecundidad de los rotíferos se compararon mediante análisis de varianza (ANOVA) de una vía, utilizando el programa estadístico Statistix V.1.0, previo cumplimiento de los supuestos de: normalidad del error (prueba de Wilk-Sahpiro), homogeneidad de las varianzas (prueba de Bartlett) y aditividad de los efectos (prueba de Tukey). Los datos que mostraron diferencias significativas $(\mathrm{p}<0.05)$ se les aplicó la prueba de Dunnet, con el fin de establecer diferencias grupales, siguiendo las recomendaciones de Zar (1984).

\section{RESULTADOS}

Contenido de proteínas y lípidos totales: Los contenidos de proteínas y lípidos totales de las diferentes pastas (\% con base a masa seca) no mostraron diferencias significativas (Dunnet, $\mathrm{p}>0.05$ ) ni entre ellas ni con respecto al cultivo fresco (Fig. 1). Los valores promedio (media \pm desviación estándar) para estos parámetros fueron $40.0 \pm 2.3 \%$ de proteínas y $12.0 \pm 1.4 \%$ de lípidos.

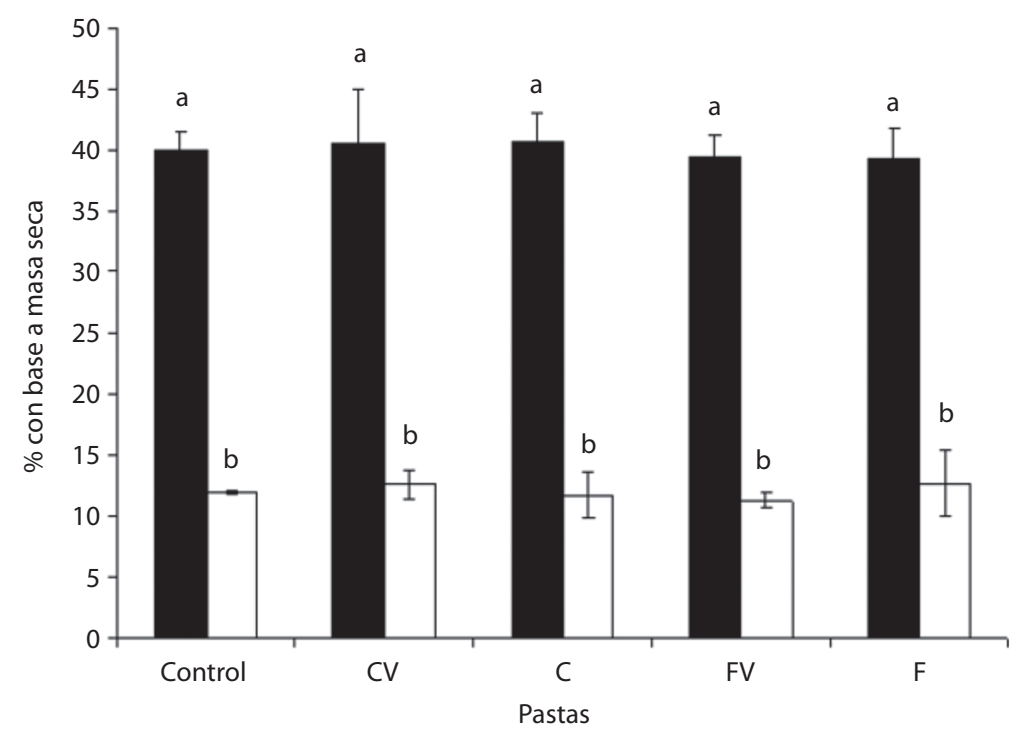

Fig. 1. Contenido (\%) de proteínas y lípidos totales de las pastas de Rhodomonas salina. $\square$ Proteínas totales, $\square$ Lípidos totales. CV: centrifugada con vitamina C, C: centrifugada sin vitamina C. FV: floculada y con adición de vitamina C, F: floculada y sin adición de vitamina C. Control: cultivo fresco de $R$. salina. Letras comunes $(\mathrm{a}, \mathrm{b})$ indican grupos estadísticamente homogéneos (Dunnet, $\mathrm{p}>0.05$ ).

Fig. 1. Total protein and lipid contents (\%) of pastes of Rhodomonas salina. $\mathbf{a}$ Total proteins, $\square$ Total lipids. CV: centrifuged and preserved with vitamin $\mathrm{C}, \mathrm{C}$ : centrifuged and preserved without vitamin C. FV: flocculated and preserved with vitamin $\mathrm{C}$ and F: flocculated and without addition of vitamin C. Control: fresh culture of $R$. salina. Common letters $(\mathrm{a}, \mathrm{b})$ indicate statistically homogeneous groups (Dunnet, $\mathrm{p}>0.05$ ). 
Perfil de ácidos grasos: El perfil de ácidos grasos de las cuatro pastas de $R$. salina $(\mathrm{FV}$, $\mathrm{F}, \mathrm{CV}$ y $\mathrm{C}$ ), almacenadas durante cuatro semanas a $-20^{\circ} \mathrm{C}$ presentó pocas variaciones con respecto al control (cultivo fresco) (Cuadro 1).
Las mayores variaciones se observaron en el contenido total de los ácidos grasos poliinsaturados (PUFAs), los cuales mostraron diferencias significativas entre las diferentes pastas (Dunnet, $\mathrm{p}<0.05$ ).

\section{CUADRO 1}

Perfil de ácidos grasos (\% del total de ácidos grasos) de las pastas de Rhodomonas salina

TABLE 1

Fatty acid profile (\% of total fatty acids) of different pastes of Rhodomonas salina

\begin{tabular}{|c|c|c|c|c|c|}
\hline Ácidos grasos & $\mathrm{FV}^{*}$ & $\mathrm{~F}^{*}$ & $\mathrm{CV}^{*}$ & $\mathrm{C}^{*}$ & Control* \\
\hline $12: 0$ & $3.20 \pm 0.160$ & $3.80 \pm 0.228$ & $3.49 \pm 0.279$ & $3.41 \pm 0.307$ & $3.49 \pm 0.262$ \\
\hline $14: 0$ & $4.96 \pm 0.198$ & $4.80 \pm 0.288$ & $4.90 \pm 0.392$ & $4.96 \pm 0.446$ & $5.10 \pm 0.383$ \\
\hline $16: 0$ & $13.30 \pm 0.798$ & $13.90 \pm 0.834$ & $14.50 \pm 1.160$ & $13.10 \pm 1.179$ & $13.70 \pm 1.028$ \\
\hline $17: 0$ & $0.80 \pm 0.040$ & $0.79 \pm 0.047$ & $0.76 \pm 0.061$ & $0.75 \pm 0.068$ & $0.80 \pm 0.060$ \\
\hline 18:0 & $7.10 \pm 0.568$ & $7.00 \pm 0.420$ & $5.90 \pm 0.472$ & $6.60 \pm 0.594$ & $4.10 \pm 0.308$ \\
\hline 20:0 & $0.19 \pm 0.011$ & $0.20 \pm 0.012$ & $0.17 \pm 0.014$ & $0.10 \pm 0.009$ & $0.20 \pm 0.015$ \\
\hline $22: 0$ & $0.95 \pm 0.067$ & $0.18 \pm 0.011$ & $0.30 \pm 0.024$ & $1.10 \pm 0.099$ & $1.10 \pm 0.082$ \\
\hline $23: 0$ & $1.20 \pm 0.096$ & $1.15 \pm 0.069$ & $0.90 \pm 0.072$ & $0.91 \pm 0.082$ & $1.24 \pm 0.093$ \\
\hline $24: 0$ & $0.29 \pm 0.015$ & $0.17 \pm 0.010$ & $0.38 \pm 0.030$ & $0.40 \pm 0.036$ & $0.60 \pm 0.045$ \\
\hline$\Sigma$ Saturados & $31.99^{\mathrm{a}}$ & $31.99^{\mathrm{a}}$ & $31.30^{\mathrm{a}}$ & $31.33^{\mathrm{a}}$ & $30.33^{\mathrm{a}}$ \\
\hline $16: 1 n-7$ & $3.49 \pm 0.209$ & $3.73 \pm 0.224$ & $3.60 \pm 0.288$ & $3.80 \pm 0.342$ & $4.00 \pm 0.300$ \\
\hline $16: 1 n-9$ & $0.60 \pm 0.036$ & $0.65 \pm 0.039$ & $0.61 \pm 0.049$ & $0.60 \pm 0.054$ & $0.70 \pm 0.053$ \\
\hline $17: 1 n-8$ & $0.11 \pm 0.007$ & $0.10 \pm 0.006$ & $0.12 \pm 0.010$ & $0.12 \pm 0.011$ & $0.12 \pm 0.009$ \\
\hline $18: 1 n-9$ & $4.14 \pm 0.248$ & $4.10 \pm 0.246$ & $4.18 \pm 0.334$ & $4.15 \pm 0.373$ & $4.20 \pm 0.315$ \\
\hline $18: 1 n-7$ & $12.30 \pm 0.738$ & $12.65 \pm 0.759$ & $11.70 \pm 0.936$ & $11.80 \pm 1.062$ & $12.66 \pm 0.949$ \\
\hline $20: 1 n-11$ & $0.25 \pm 0.015$ & $0.22 \pm 0.013$ & $0.15 \pm 0.012$ & $0.12 \pm 0.011$ & $0.25 \pm 0.019$ \\
\hline $20: 1 n-7$ & $0.30 \pm 0.018$ & $0.20 \pm 0.012$ & 0.220 .018 & $0.22 \pm 0.020$ & $0.30 \pm 0.023$ \\
\hline $22: 1 n-11$ & $0.13 \pm 0.008$ & $0.10 \pm 0.006$ & $0.09 \pm 0.007$ & $0.20 \pm 0.018$ & $0.21 \pm 0.016$ \\
\hline$\Sigma$ Monoinsaturados & $21.32^{\mathrm{a}}$ & $21.75^{\mathrm{a}}$ & $20.67^{\mathrm{a}}$ & $21.01^{\mathrm{a}}$ & $22.44^{\mathrm{a}}$ \\
\hline $18: 2 n-6$ & $11.10 \pm 0.555$ & $10.97 \pm 0.658$ & $12.10 \pm 0.968$ & $11.95 \pm 1.076$ & $10.20 \pm 0.765$ \\
\hline $18: 3 n-6$ & $3.23 \pm 0.162$ & $3.17 \pm 0.190$ & $4.39 \pm 0.351$ & $4.31 \pm 0.388$ & $4.38 \pm 0.328$ \\
\hline $18: 3 n-3$ & $8.30 \pm 0.415$ & $8.10 \pm 0.486$ & $8.51 \pm 0.681$ & $8.00 \pm 0.720$ & $8.50 \pm 0.637$ \\
\hline $18: 4 n-3$ & $12.08 \pm 0.604$ & $12.10 \pm 0.726$ & $11.59 \pm 0.811$ & $12.24 \pm 1.102$ & $12.60 \pm 0.945$ \\
\hline $20: 2 n-6$ & $0.08 \pm 0.004$ & $0.09 \pm 0.005$ & $0.10 \pm 0.008$ & $0.06 \pm 0.005$ & $0.10 \pm 0.008$ \\
\hline $20: 3 n-6$ & $0.09 \pm 0.005$ & $0.08 \pm 0.005$ & $0.06 \pm 0.005$ & $0.09 \pm 0.008$ & $0.10 \pm 0.008$ \\
\hline $20: 3 n-3$ & $0.30 \pm 0.015$ & $0.30 \pm 0.018$ & $0.29 \pm 0.023$ & $0.28 \pm 0.025$ & $0.36 \pm 0.027$ \\
\hline $20: 4 n-6$ (ARA) & $1.15 \pm 0.058$ & $1.20 \pm 0.072$ & $1.35 \pm 0.108$ & $1.37 \pm 0.123$ & $1.40 \pm 0.105$ \\
\hline 20:5n-3 (EPA) & $3.10 \pm 0.155^{\mathrm{a}}$ & $3.25 \pm 0.195^{\mathrm{a}}$ & $4.22 \pm 0.338^{b}$ & $4.15 \pm 0.373^{\mathrm{b}}$ & $4.00 \pm 0.300^{\mathrm{b}}$ \\
\hline $21: 4 n-6$ & $0.21 \pm 0.011$ & $0.23 \pm 0.014$ & $0.25 \pm 0.015$ & $0.24 \pm 0.022$ & $0.50 \pm 0.038$ \\
\hline $22: 4 n-6$ & $0.03 \pm 0.002$ & $0.04 \pm 0.002$ & $0.05 \pm 0.004$ & $0.05 \pm 0.004$ & $0.05 \pm 0.004$ \\
\hline $22: 5 n-6$ & $0.02 \pm 0.001$ & $0.12 \pm 0.007$ & $0.20 \pm 0.016$ & $0.05 \pm 0.004$ & $0.05 \pm 0.004$ \\
\hline $22: 5 n-3$ & $0.04 \pm 0.002$ & $0.05 \pm 0.003$ & $0.05 \pm 0.004$ & $0.06 \pm 0.005$ & $0.07 \pm 0.005$ \\
\hline 22:6n-3 (DHA) & $3.50 \pm 0.175^{\mathrm{a}}$ & $3.40 \pm 0.204^{\mathrm{a}}$ & $4.54 \pm 0.363^{b}$ & $4.80 \pm 0.432^{\mathrm{b}}$ & $4.80 \pm 0.360^{\mathrm{b}}$ \\
\hline$\Sigma$ Poliisanturados & $43.23^{\mathrm{a}}$ & $43.10^{\mathrm{a}}$ & $47.70^{\mathrm{b}}$ & $47.64^{\mathrm{b}}$ & $47.11^{b}$ \\
\hline Total & 96.64 & 96.84 & 99.67 & 99.98 & 99.88 \\
\hline
\end{tabular}

Abreviaturas como en la Fig. 1. Letras comunes $(a, b)$ en una misma fila indican grupos estadísticamente homogéneos (Dunnet, $\mathrm{p}>0.05)$.*=Promedio \pm desviación estándar. 
Las pastas centrifugadas ( $\mathrm{CV}$ y $\mathrm{C}$ ) presentaron porcentajes de PUFAs totales similares al control (47\%), valor que fue significativamente superior (Dunnet, $\mathrm{p}<0.05$ ) al obtenido en las pastas floculadas (FV y F) (43\%). En el caso de los ácidos grasos esenciales EPA y DHA, se obtuvieron diferencias significativas (Dunnet, $\mathrm{p}<0.05$ ) entre las distintas pastas microalgales. En las pastas centrifugadas, los porcentajes de estos ácidos grasos resultaron estadísticamente similares a los obtenidos en el cultivo control (EPA, 4\% y DHA, 4.7\%), valores que disminuyeron significativamente en las pastas floculadas con quitosano (EPA, 3.1\% y DHA, $3.4 \%$ ) (Cuadro 1).

Relación feofitina $a$ /clorofila $a$ : La relación feofitina $a$ /clorofila $a$ mostró diferencias significativas entre las pastas centrifugadas y floculadas (Dunnet, $\mathrm{p}<0.05$ ). Como se observa en la Fig. 2 la relación feofitina a/clorofila $a$ de las pastas obtenidas por centrifugación varió entre 0.09 y 0.11 ; valores muy bajos y similares al obtenido para el cultivo control (Dunnet, $\mathrm{p}>0.05$ ). Por el contrario, las pastas obtenidas por floculación con quitosano presentaron valores mucho más elevados (1.25 a 1.45), sin diferencias significativas entre ellos (Dunnet, $\mathrm{p}>0.05$ ), lo que muestra que la adición de vitamina $\mathrm{C}$ a las pastas no evitó la degradación de la clorofila $a$ durante el tiempo de almacenamiento.

Parámetros de crecimiento de $B$. plicatilis: Los valores mayores de densidad poblacional, tasa instantánea de crecimiento, productividad y fecundidad al quinto día de cultivo variaron entre 316-326rotífe$\mathrm{ros} / \mathrm{mL} ; \quad 0.23-0.24$ rotíferos/día; 40 590-45 120rotíferos/L/día y 1.46-1.52huevos/hembra, respectivamente (Fig. 3, Cuadro 2). Posterior al quinto día de cultivo, se observó deterioro en todos los cultivos de rotíferos, manifestado por la aparición de olores desagradables y abundancia de espuma en la superficie de los mismos.

Los parámetros de crecimiento y fecundidad de B. plicatilis al quinto día de alimentación con las pastas microalgales generadas por centrifugación $(\mathrm{CV}$ y $\mathrm{C})$, no mostraron diferencias significativas (Dunnet, $\mathrm{p}>0.05$ ) con

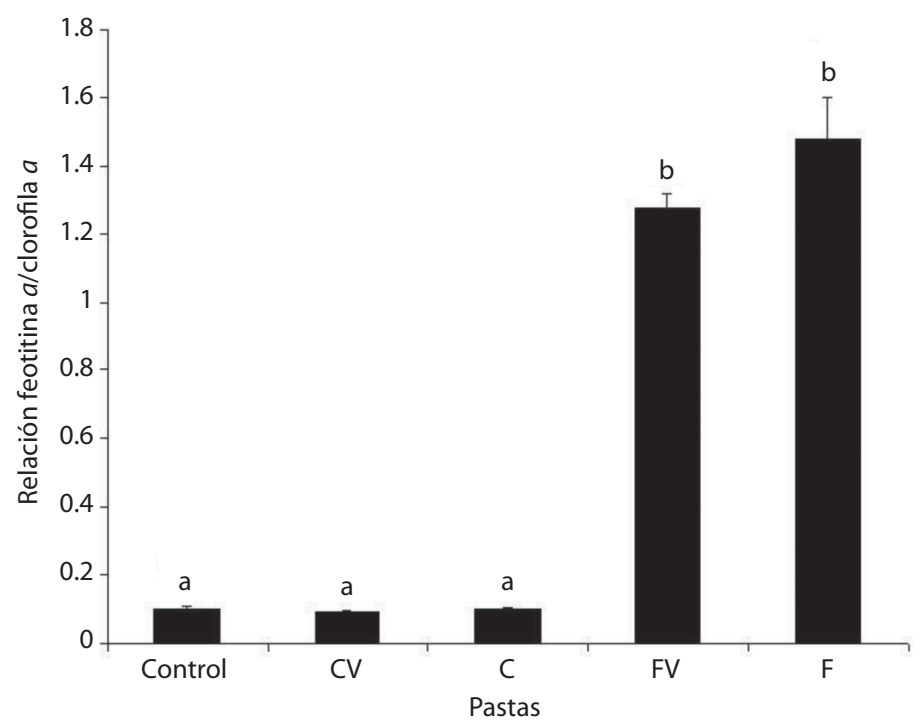

Fig. 2. Relación feofitina a/clorofila $a$ de las pastas de Rhodomonas salina. Abreviaturas como en la Fig. 1. Letras comunes $(\mathrm{a}, \mathrm{b})$ indican grupos estadísticamente homogéneos (Dunnet, $\mathrm{p}>0.05$ ).

Fig. 2. Pheophytin a/chlorophyll $a$ relation of pastes of Rhodomonas salina. Abbreviations as in Fig. 1. Common letters (a,b) indicate statistically homogeneous groups (Dunnet, $\mathrm{p}>0.05$ ). 


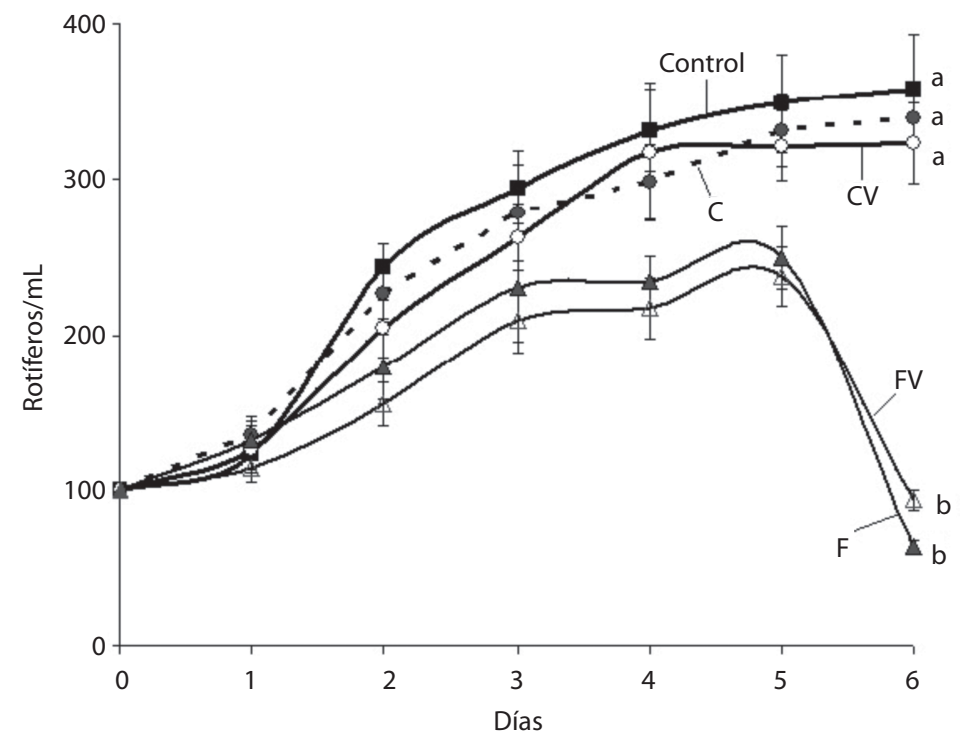

Fig. 3. Crecimiento (rotíferos/mL) del rotífero Brachionus plicatilis alimentado con las diferentes pastas de Rhodomonas salina. Abreviaturas como en la Fig. 1. Letras comunes (a,b) indican grupos estadísticamente homogéneos (Dunnet, $\mathrm{p}>0.05)$. Fig. 3. Growth (rotifers $/ \mathrm{mL}$ ) of the rotifer Brachionus plicatilis fed with different pastes of Rhodomonas salina. Abbreviations as in Fig. 1. Common letters (a,b) indicate statistically homogeneous groups (Dunnet, $\mathrm{p}>0.05$ ).

CUADRO 2

Crecimiento y fecundidad de B. plicatilis alimentado con diferentes pastas de Rhodomonas salina

TABLE 2

Growth and fecundity of $B$. plicatilis fed different pastes of Rhodomonas salina

\begin{tabular}{lcccc} 
& $\begin{array}{c}\text { Densidad máxima } \\
\text { (rotíferos/mL)* }\end{array}$ & $\begin{array}{c}\text { Tasa instantánea de } \\
\text { crecimiento } \\
\text { (rotíferos/día)* }\end{array}$ & $\begin{array}{c}\text { Productividad } \\
\text { (rotíferos/L/día)* }\end{array}$ & $\begin{array}{c}\text { Fecundidad } \\
\text { (huevos/hembra)* }\end{array}$ \\
Control & $320.5 \pm 26.24^{\mathrm{a}}$ & $0.23 \pm 0.016^{\mathrm{a}}$ & $40.59 \times 10^{3} \pm 3039^{\mathrm{a}}$ & $1.50 \pm 0.09^{\mathrm{a}}$ \\
$\mathrm{CV}$ & $325.6 \pm 23.40^{\mathrm{a}}$ & $0.24 \pm 0.014^{\mathrm{a}}$ & $45.12 \times 10^{3} \pm 4680^{\mathrm{a}}$ & $1.46 \pm 0.10^{\mathrm{a}}$ \\
$\mathrm{C}$ & $315.7 \pm 20.47^{\mathrm{a}}$ & $0.23 \pm 0.013^{\mathrm{a}}$ & $43.14 \times 10^{3} \pm 4094^{\mathrm{a}}$ & $1.52 \pm 0.06^{\mathrm{a}}$ \\
$\mathrm{FV}$ & $210.4 \pm 12.18^{\mathrm{b}}$ & $0.15 \pm 0.012^{\mathrm{b}}$ & $22.08 \times 10^{3} \pm 2436$ & $0.80 \pm 0.04^{\mathrm{b}}$ \\
$\mathrm{F}$ & $212.4 \pm 17.80^{\mathrm{b}}$ & $0.15 \pm 0.017^{\mathrm{b}}$ & $22.48 \times 10^{3} \pm 3560$ & $0.86 \pm 0.05^{\mathrm{b}}$ \\
\hline
\end{tabular}

Abreviaturas como en la Fig. 1. Letras comunes $(\mathrm{a}, \mathrm{b})$ en una misma columna indican grupos estadísticamente homogéneos (Dunnet, $\mathrm{p}>0.05)$.*=Promedio \pm desviación estándar.

respecto a los parámetros de los individuos cultivados con el alimento control (cultivo fresco). Por otro lado, los rotíferos alimentados con las pastas obtenidas por floculación (FV y F) mostraron parámetros de crecimiento y fecundidad significativamente inferiores (Dunnet, p<0.05) (Fig. 3, Cuadro 2).

\section{DISCUSIÓN}

Este estudio demuestra la factibilidad de usar pastas de Rhodomonas salina como alimento para $B$. plicatilis, un rotífero ampliamente utilizado en acuicultura como vehículo de nutrientes en la alimentación de especies 
marinas en cultivo (Lubzens et al. 2001). La centrifugación o floculación no afectó la composición de proteínas y lípidos de las pastas, así como tampoco las afectó el almacenamiento a $-20^{\circ} \mathrm{C}$ por 4 semanas.

Por otro lado, las pastas obtenidas por centrifugación conservaron la proporción de PUFAs esenciales, EPA y DHA similares al cultivo fresco y produjeron mayor crecimiento y fecundidad de B. plicatilis, que las pastas obtenidas por floculación con quitosano (Cuadro 1, 2, Fig. 3). Este último hallazgo respalda un hecho que ha sido previamente destacado para numerosas especies (Levine \& Sulkin 1984, Pernet \& Tremblay 2004): la importancia de los PUFAs como nutrientes esenciales, y convierte la diferencia del método de concentración de microalgas en un hecho muy relevante.

Además, las pastas obtenidas por centrifugación mostraron una mayor estabilidad bioquímica que las obtenidas por floculación, tal como se evidencia en sus perfiles de ácidos grasos (Cuadro 1) y en su baja relación feofitina $a$ clorofila $a$ (Fig. 2). Este comportamiento se debería a que las células sufren menor daño físico al ser centrifugadas, resultado que se respalda en las investigaciones de Beneman et al. (1980), Montaini et al. (1995), Albentosa et al. (1997), D'Souza et al. (2000), Heasman et al. (2000), Molina-Grima et al. (2003) y Nunes et al. (2009), quienes coinciden en las ventajas comparativas de este método de cosecha.

Algunos autores han indicado que la estabilidad bioquímica, así como la viabilidad celular de las pastas de microalgas puede mejorarse a través del uso de aditivos, tipo antioxidantes. Heasman et al. (2000) señalaron que las pastas de Skeletonema con adición de vitamina $\mathrm{C}$ como antioxidante, mantienen una calidad nutricional superior a aquellas que carecen de este aditivo; sin embargo, en nuestro estudio las pastas que contenían vitamina $\mathrm{C}$ no mostraron diferencias significativas, en cuanto a su composición bioquímica, con respecto a las que no contenían este aditivo. Resultados similares fueron obtenidos por Robert et al. (2001), quienes encontraron que las pastas de Tetraselmis suecica, obtenidas por centrifugación y almacenadas sin vitamina $\mathrm{C}$, a $4^{\circ} \mathrm{C}$, durante cinco semanas, mantuvieron estable su perfil de ácidos grasos y su contenido de lípidos y proteínas. De igual forma, Ponis et al. (2003b) demostraron que pastas de Pavlova lutheri preservadas a 1 y $4^{\circ} \mathrm{C}$, sin vitamina $\mathrm{C}$, mantienen inalterable su valor nutricional durante 27 días. Esta concordancia de resultados permite concluir que la baja temperatura sería suficiente para mantener la calidad nutricional de los concentrados de microalgas, no siendo necesaria la adición de preservantes en muchos casos.

A pesar de las ventajas de la centrifugación para generar concentrados de microalgas, ésta presenta el inconveniente de ser costosa y poco práctica cuando se trabaja con grandes volúmenes de cultivo (Knuckey et al. 2006). Lo anterior ha motivado el uso de floculantes como un método de cosecha más económico y adecuado para tratar grandes volúmenes de cultivo; sin embargo, se ha planteado que las pastas floculadas suelen sufrir mayor deterioro que las centrifugadas debido, principalmente, a que los cambios en el $\mathrm{pH}$ y el desequilibrio del potencial iónico, producido durante el proceso de floculación, pueden inducir estrés químico en las células de microalgas; lo cual, sin embargo, dependerá de la naturaleza de la pared celular de la especie floculada (Brown \& Robert 2002).

En el presente trabajo se observó que tanto las pastas floculadas con quitosano como las centrifugadas mantuvieron estable su contenido de proteínas y lípidos, durante el periodo de almacenamiento; no obstante, en las pastas floculadas, el contenido de clorofila $a$ se vio negativamente afectado, con un concomitante incremento en su producto de degradación: feofitina $a$. Ponis et al. (2003a) obtuvieron resultados similares con las biomasas floculadas de Chaetoceros calcitrans y Pavlova lutheri, las cuales mantuvieron estable su contenido proteico y lipídico, durante tres semanas de almacenamiento a $1^{\circ} \mathrm{C}$, a pesar de haber experimentado un incremento de la relación feofitina $a$ /clorofila $a$.

La estabilidad del perfil de ácidos grasos obtenida en esta investigación en las pastas 
centrifugadas de Rhodomonas salina, luego del proceso de almacenamiento, ha sido previamente observada en otras especies de microalgas como Tetraselmis suecica e Isochrysis galbana, cuyas pastas han mantenido estable su perfil de ácidos grasos cuando se preservan a bajas temperaturas (Molina-Grima et al. 1994, Montaini et al. 1995).

Los resultados de esta investigación indican que la biomasa centrifugada y congelada de $R$. salina puede ser usada como alimento del rotífero Brachionus plicatilis. Al comparar la máxima densidad de rotíferos (325.6rotíferos $/ \mathrm{mL}$ ) obtenida con las pastas microalgales centrifugadas se observa que ésta es superior a las reportadas por Hung (1988) y Guevara et al. (1996), y similar a las obtenidas por Gómez \& Gómez (1997) quienes utilizaron levadura de panificación como alimento, y obtuvieron densidades de 60, 218 y 336rotíferos $/ \mathrm{mL}$, respectivamente. De igual forma, nuestros resultados superan a los valores obtenidos por Romero \& Otero (2004) (214rotíferos/ml) y Romero et al. (2006) (250rotíferos $/ \mathrm{mL}$ ), cuando alimentaron a $B$. plicatilis con pastas de Chlorella centrifugada y mantenida a $4^{\circ} \mathrm{C}$. Los sistemas de cultivos más tecnificados, que incluyen alimentación continua con pasta de Nannochloropsis sp., han permitido obtener mayores densidades de rotíferos (500-1 500Rotíferos/L) (Pfeiffer \& Ludwig 2002). La máxima productividad de rotíferos obtenida en este trabajo (45.15 $\times 10^{3}$ rotíferos/L/día) con las pastas centrifugadas es similar a la lograda por Gómez \& Gómez (1997) cuando alimentaron a B. plicatilis con levadura de panificación y superior a las obtenidas por Navarro \& Yúfera (1998) y Romero et al. (2006) cuando usaron como alimento pasta de Chlorella y polvo liofilizado de Nannochloropsis oculata, respectivamente.

Otro criterio de mucha importancia en la evaluación de los cultivos de rotíferos es la fecundidad, estimada a partir de la relación huevos/hembra, ya que permite visualizar el estado fisiológico de la población en un momento dado. En esta investigación, la máxima fecundidad se obtuvo con las pastas microalgales centrifugadas (1.5huevos/hembra). Esta fecundidad es superior a las obtenidas por Rueda (1996) (0.6-1 .05huevos/hembra) con las microalgas Nannochloris sp., Nannochloropsis sp., Chlorella sp. y polvo de Spirulina sp.; y superan también los valores reportados por Romero et al. (2006), cuando alimentaron a $B$. plicatilis con pasta de Chlorella centrifugada, obteniendo 1 a 1.2 huevos/hembra.

A pesar de que en esta investigación no se analizó la composición bioquímica del rotífero $B$. plicatilis, se puede inferir que éstos debieran presentar una composición bioquímica adecuada, dado que muchos estudios han demostrado que la calidad nutricional de este organismo depende de la composición bioquímica de la microalga utilizada para su alimentación (Lubzens et al. 1995, Dhert et al. 2001). Recientemente, Seychelles et al. (2009) evidenciaron que el perfil de los ácidos grasos de los rotíferos fue similar al de las microalgas usadas para su alimentación (microalgas frescas o en forma de pasta).

Las pastas centrifugadas de $R$. salina caracterizadas en este estudio, también podrían utilizarse, directamente, como alimento de larvas y juveniles de moluscos bivalvos, debido a su composición bioquímica, específicamente su perfil de ácidos grasos. Numerosos estudios han demostrado que las microalgas con altos contenidos de EPA y DHA favorecen el crecimiento de juveniles de Ostrea edulis (Enright et al. 1986) y larvas de Patinopecten yessoensis (Whyte et al. 1989). De igual forma, Nell \& O'Connor (1991) encontraron que las pastas de Pavlova lutheri y Chaetoceros calcitrans refrigeradas a $4^{\circ} \mathrm{C}$ por una o dos semanas produjeron mayor crecimiento larvario de la ostra Saccostrea commercialis que el obtenido con las microalgas frescas. McCausland et al. (1999) lograron incrementar hasta en un $87 \%$ el crecimiento de juveniles de Crassostrea gigas al alimentarlas con pasta de Skeletonema costatum, cosechada mediante centrifugación y almacenada a $4^{\circ} \mathrm{C}$. Cabe destacar que el DHA es, en general, un ácido graso escaso en las microalgas, por lo que su contenido relativamente alto en $R$. salina (Cuadro 1) la destaca 
como una especie de especial valor nutricional para la acuicultura.

Además de las ventajas ya mencionadas de utilizar pastas de microalgas como alimento en acuicultura, se ha planteado que su uso podría ser incluso más beneficioso para la salud de los animales que el uso de caldos de microalgas, ya que el medio de cultivo de las microalgas puede contener toxinas y abundantes bacterias, las que pueden inhibir el crecimiento de diferentes organismos animales en cultivo (DeMott et al. 1991, Kiviranta et al. 1991, O’Connor et al. 1992, Lee \& Shen 2004, Sun et al. 2008).

Finalmente, se concluye que la centrifugación, como método de cosecha, y la congelación a $-20^{\circ} \mathrm{C}$, durante cuatro semanas, sin adición de vitamina $\mathrm{C}$, permiten mantener la calidad nutricional de la pasta de $R$. salina similar a la del alga fresca y puede ser utilizada como alimento para Brachionus plicatilis.

\section{AGRADECIMIENTOS}

Este trabajo fue financiado por la Universidad de Concepción, Chile a través del proyecto DIUC N ${ }^{\circ} 208.111 .050-1.0$ y por el Consejo de Investigación de la Universidad de Oriente, Venezuela (proyecto CI.-2-030603-1282/06). Se agradece el apoyo brindado para los análisis de los ácidos grasos a los profesionales: Elena Palacios, Olivia Arjona y Laura Correón del CIBNOR, México.

\section{RESUMEN}

Pastas de Rhodomonas salina, obtenidas mediante centrifugación y floculación con quitosano y preservadas con o sin vitamina $\mathrm{C}$, a $-20^{\circ} \mathrm{C}$ fueron evaluadas bioquímicamente y proporcionadas como alimento al rotífero $\mathrm{Bra}$ chionus plicatilis. Las pastas microalgales: (1) centrifugada y con vitamina $\mathrm{C}(\mathrm{CV}),(2)$ centrifugada y sin vitamina $\mathrm{C}$ (C), (3) floculada y con vitamina C (FV) y (4) floculada y sin adición de vitamina $\mathrm{C}(\mathrm{F})$; mantuvieron sus contenidos de proteínas y lípidos totales similares al cultivo control, con valores de $40.0 \pm 2.32 \%$ y $12.0 \pm 1.45 \%$, respectivamente. La relación feofitina $a$ /clorofila $a$ fue similar (0.09-0.11) entre las pastas centrifugadas y el cultivo control, pero mayor en las pastas floculadas (1.28-1.48). Las pastas centrifugadas presentaron porcentajes de PUFAs totales, EPA y DHA similares al cultivo control (PUFAs: 47\%, EPA:
4\% y DHA: $4.7 \%$ ) y superiores al de las pastas floculadas. Las pastas obtenidas por centrifugación indujeron un crecimiento del rotífero igual al obtenido con el alimento control (densidad máxima: 320rotíferos/mL; tasa instantánea de crecimiento: 0.23rotíferos/día, fecundidad: 1.49huevos/ hembra y productividad: $43 \times 10^{3}$ rotíferos/L/día). Se concluye que la pasta de $R$. salina centrifugada y congelada a $-20^{\circ} \mathrm{C}$, durante cuatro semanas, sin adición de vitamina $\mathrm{C}$, mantiene su calidad nutricional similar a la del alga fresca y puede ser usada como alimento de Brachionus plicatilis.

Palabras clave: pasta de microalgas, acuicultura, Rhodomonas salina, floculación, rotíferos.

\section{REFERENCIAS}

Albentosa, M., A. Pérez-Camacho, U. Labarta \& M.J. Fernández-Reiriz. 1997. Evaluation of freeze-dried microalgal diets for the seed culture of Ruditapes decussatus using physiological and biochemical parameters. Aquaculture 154: 305-321.

Alvarez, Z. \& J. Ewald. 1990. Efectos de la salinidad y la dieta sobre el desarrollo larvario de Sesarma ricordi (Milne Edwards, 1853) (Decapoda, Grapside). Scient. Mar. 54: 55-60.

Beneman, J., B. Koopman, D. Eisenberg \& R. Goebel. 1980. Development of micro-algae harvesting and high rate pond technologies in California, p. 457495. In G. Shelef \& C. Soeder (eds.). Algae biomass. Elsevier/North Holland Biomedical, Amsterdam, Holanda.

Bermúdez, J., N. Rosales, C. Loreto, B. Briceño \& E. Morales. 2004. Exopolysaccharide, pigment and protein production by the marine microalga Chroomonas sp. in semicontinuos cultures. World. J. Microbiol. Biotechnol. 20: 179-183.

Bonaldo, A., A. Badiani, S. Testi, G. Corso, A.L. Mordenti \& P.P. Gatta. 2005. Use of centrifuged and preserved microalgae from feeding juvenile Manila clam (Tapes philippinarum): effects on growth and fatty acid composition. Ital. J. Anim. Sci. 4: 375-384.

Borowitzka, M. 1997. Microalgae for aquaculture: opportunities and constraints. J. Appl. Phycol. 9: 393-401.

Brown, M. \& R. Robert. 2002. Preparation and assessment of microalgal concentrates as feeds for larval and juvenile Pacific oyster (Crassostrea gigas). Aquaculture 207: 289-309.

Cavalin, F. \& C. Weirich. 2009. Larval performance of aquacultured Florida pompano (Trachinotus 
carolinus) fed rotifers (Brachionus plicatilis) enriched with selected commercial diets. Aquaculture 292: 67-73.

Chini Zittelli, G., L. Rodolfi \& M.R. Tredici. 2003. Mass cultivation of Nannochloropsis sp. in annular reactors. J. Appl. Phycol. 15: 107-114.

Conceição, L., M. Yúfera, P. Makridis, S. Morais \& M. Dinis. 2010. Live feeds for early stages of fish rearing. Aquaculture Res. 41: 613-640.

DeMott, W., Q.X. Zhang \& W.W. Carmichael. 1991. Effects of toxic cyanobacteria and purified toxins on the survival and feeding of a copepod and three species of Daphnia. Limnol. Oceanogr. 36: 1346-1457.

Dhert, P., G. Rombaut, G. Suantika \& P. Sorgeloos. 2001. Advancement of rotifer culture and manipulation techniques in Europe. Aquaculture 200: 129-146.

D`Souza, F., D. Lecossois, M. Heasman, J. Diemar, C. Jackson \& R. Pendrey. 2000. Evaluation of centrifuged microalgae concentrates as diets for Penaeus monodon (Fabricius) larvae. Aquaculture Res. 31: 661-670.

Dunstan, G., M. Brown \& J. Volkman. 2005. Cryptophyceae and rhodophyceae: chemotaxonomy, phylogeny, and application. Phytochemistry 66: 2557-2570.

Enright, C., G.F. Newkirk, J.S. Craigie \& J.D. Castell. 1986. Growth of juvenile Ostrea edulis L. fed Chaetoceros gracilis Schütt of varied chemical composition. J. Exp. Mar. Biol. Ecol. 96: 15-26.

Fernández, M., A. Pérez, M. Ferreiro, J. Blanco, M. Planas, M.J. Campos \& U. Labarta. 1989. Biomass production and variation on the biochemical profile (total proteins, carbohydrates, RNA, lipids and fatty acids) of seven species of marine microalgae. Aquaculture 83: 17-37.

Gallagher, M., H. Daniels \& J. Harcke. 2001. Influence of the enrichment time with algae paste preservations on the fatty acid content of rotifers. W. Aquacult. 32: $59-65$.

Gómez, O. \& A. Gómez. 1997. Cultivo masivo del rotífero Brachionus plicatilis (Muller, 1786) (CEPA ARAYA) con diferentes tipos de levadura. Saber 9: 332-35.

Guevara, M., A. Gómez \& N. Marín. 1996. Utilización de microalgas y levadura en el cultivo de una cepa de Brachionus plicatilis (O: F. Müller, 1786) (Rotifera: Monogonta) de las salinas de Araya, Venezuela. Acta Cient. Venez. 47: 255-261.
Guillard, R. 1975. Culture of phytoplankton for feeding marine invertebrates, p. 26-60. In W.L. Smith \& M.H. Chanley. Culture of marine invertebrate animals. Plenum, Nueva York, Nueva York, EEUU.

Heasman, M., J. Diemar, W. O Connor, T. Sushames \& L. Foulkes. 2000. Development of extended shelf-life microalgae concentrate diets harvested by centrifugation for bivalve mollusks- a summary. Aquaculture Res. 31: 637-659.

Hill, D.R.A \& R. Wetherbee. 1989. A reappraisal of the genus Rhodomonas (Cryptophyceae). Phycologia 28: $143-158$.

Hung, M. 1988. Ensayo de cultivo de una cepa de rotífero Brachionus plicatilis aislada en Venezuela. Rev. Latinoamer. Acuicult. 40: 82-112.

James, C., M. Bou-Abbas, A. Al-Khars, S. Al-Hinty \& A. Salman. 1983. Production of the rotifer Brachionus plicatilis for aquaculture in Kuwait. Hydrobiologia 104: 77-84.

Kiviranta, J., K. Sivonen, S. Niemela \& K. Huovinen. 1991. Detection of toxicity of cyanobacteria by Artemia salina bioassay. Environ. Toxicol. Water 6: 423-436.

Knuckey, R., M. Brown, R. Robert \& D. Frampton. 2006. Production of microalgal concentrates by flocculation and their assessment as aquaculture feeds. Aquacult. Engi. 35: 300-313.

Lee, Y. \& H. Shen. 2004. Basic culture techniques, p. 40-57. In A. Richmond. Handbook of microalgal culture: biotechnology and applied phycology. Blackwell, Iowa, Iowa, EEUU.

Levine, D. \& S. Sulkin. 1984. Nutritional significance of long-chain polyunsaturated fatty acids to the zoea development of the brachyuran crab Eurypanopeus depresssus Smith. J. Exp. Mar. Biol. Ecol. 81: 211-223.

Liao, I., H. Su \& J. Lin. 1983. Larval foods for penaied praws, p. 43-69. In J.P. Mcvey (ed.). Handbook of mariculture. C.R.C, Boca Ratón, Florida, EEUU.

Lorenzen, C. 1967. Determination of chlorophyll and phaeopigments: spectrophotometric equations. Limnol. Oceanogr. 12: 343-346.

Lowry, O., H. Rosebrough, A. Farr \& R. Randall. 1951. Protein measurement with the folin-phenol reagent. J. Biol. Chem. 193: 265-275. 
Lubzens, E., A. Marko \& A. Tietz. 1989. De novo synthesis of fatty acids in the rotifer Brachionus plicatilis. Aquaculture 47: 27-37.

Lubzens, E., O. Gibson \& A. Sukenik. 1995. Potential advantages of frozen algae (Nanochloropsis sp.) for rotifer Brachionus plicatilis. Aquaculture 133: 295-309.

Lubzens, E., O. Zamora \& Y. Barr. 2001. Biotechnology and aquaculture of rotifers. Hydrobiologia 446/447: 337-353.

Marsh, J. \& D. Weinstein. 1966. Simple charring method for determination of lipids. J. Lipids Res. 7: 574-592.

McCausland, M., M. Brown, S. Barrett, J. Diemar \& M. Heasman. 1999. Evaluation of lived and pasted microalgae as supplementary food juvenile pacific oyster (Crassostrea gigas). Aquaculture Res. 174: 323-342.

Molina-Grima, E., H. Belarbi, F. Acién, A. Robles \& Y. Chisti. 2003. Recovery of microalgal biomass and metabolites: process options and economics. Biotechnol. Adv. 20: 491-515.

Molina-Grima, E., J. Sánchez, F. García, F. Acién, D. López \& C. Segura del Castillo. 1994. Preservation of the marine microalga, Isochrysis galbana: influence on the fatty acid profile. Aquaculture 123: 377-385.

Montaini, E., G. Chini-Zittelli, M. Tredici, E. MolinaGrima, J. Fernández \& J. Sánchez. 1995. Long-term preservation of Tetraselmis suecica: influence of storage on viability and fatty acid profile. Aquaculture 134: $81-90$

Morales, J., J. De la Noue \& G. Picard. 1985. Harvesting marine microalgae species by Chitosan flocculation. Aquacult. Eng. 4: 257-270.

Navarro, N. \& C. Sarasquete. 1998. Use of freeze-dried microalgae for rearing gilthead seabream, Sparus aurata larvae. I. Growth, histology and water quality. Aquaculture 167: 179-193.

Navarro, N. \& M. Yúfera. 1998. Influence of the food ration and individual density on production efficiency of semicontinuous cultures of Brachionusfed microalgae dry powder. Hydrobiologia 387/388: 483-487.

Nell, J. \& W. O`Connor. 1991. The evaluation of fresh algae and stored algal concentrates as a food source for Sydney rock oyster, Saccostrea commercialis (Iredale and Roughley), larvae. Aquaculture 99: 277-284.
Nunes, M., A. Pereira, J. Ferreira \& F. Yasumaru. 2009. Evaluation of the microalgae paste viability produced in a mollusk hatchery in Southern Brazil. J. World Aquacult. Soc. 40: 87-94.

O`Connor, W., J. Nell \& J. Diemar. 1992. The evaluation of 12 algal species as food for juvenile Sydney rock oysters, Sacostrea commercialis (Iredale and Roughley). Aquaculture 108: 227-283.

Opstad, I., B. Starno, I. Huse \& O. Grantun-Jjeldsto. 1985. Laboratory studies on the use rotifers (Brachionus plicatilis O. F. Müller) as start-feed for cod larvae (Gadus morhua L.) Aquaculture 79: 345-351.

Pernet, F. \& R. Tremblay. 2004. Effect of varying levels of dietary essential fatty acid during early ontogeny of the sea scallop Placopecten magellanicus. J. Exp. Mar. Biol. Ecol. 310: 73-86.

Pfeiffer, T. \& G. Ludwig. 2002. Trial finds microalgae paste suitable for rotifer nutrition. Global Aquacult. Advoc. 5: 22-23.

Ponis, E., G. Parisi, G. Chini Zittelli, F. Lavista, R. Robert \& M. Tredici. 2008. Pavlova lutheri: Production, preservation and use as food for Crassostrea gigas larvae. Aquaculture 282: 97-103.

Ponis, E., R. Robert \& G. Parisi. 2003a. Nutritional value of fresh and concentrated algal diets for larval and juvenile Pacific oysters (Crassostrea gigas). Aquaculture 221: 491-505.

Ponis, E., R. Robert, G. Parisi \& M. Tredici. 2003b. Assessment of the performance of Pacific oyster (Crassostrea gigas) larvae fed with fresh and preserved Pavlova lutheri concentrates. Aquacult. Int. 11: 69-79.

Renaud, S., T. Luong-van, G. Lambrinidis \& D. Parry. 2002. Effect of temperature on growth, chemical composition and fatty acid composition of tropical microalgae grown in batch cultures. Aquaculture 211: 195-214.

Robert, R., G. Parisi, L. Rodolfi, B. Poli \& M. Tredici. 2001. Use of fresh and preserved Tetraselmis suecica for feeding Crassostrea gigas larvae. Aquaculture 192: 333-346.

Robert, R. \& P. Trintignac. 1997. Substitutes for live microalgae in mariculture: a review. Aquat. Living Resour. 10: 315-327.

Romero, T. \& C. Otero. 2004. Chlorella spp. desarrollada en los efluentes de la industria pesquera para alimentar Brachionus plicatilis. Rev. Electrón. Vet. REDVET. (Consultado: 15 octubre 2010, www.veterinaria.org/ revistas/redvet/n020204.html). 
Romero, T., Y. Villarreal \& M. Guerra. 2006. Determinación de condiciones óptimas de cultivo de Brachionus plicatilis: salinidad y aireación del medio. Bondades de Chlorella spp. desarrollada en residuales pesqueros para su alimentación. IV Congreso Iberoamericano Virtual de Acuicultura. 1004-1016. (Consultado: 15 octubre 2010, www.civa2006.org).

Rueda J. 1996. Efecto nutricional de tres microalgas y una cianobacteria en el cultivo del rotífero Brachionus plicatilis Müller 1786. Cienc. Mar. 22: 313-328.

Sato, N. \& N. Murata. 1988. Membrane Lipids. Meth. Enzymol. 167: 251-259.

Seychelles, L., C. Audet, R. Tremblay, R. Fournier \& F. Pernet. 2009. Essential fatty acid enrichment of cultured rotifers (Brachionus plicatilis, Müller) using frozen-concentrated microalgae. Aquacult. Nutr. 15: 431-439.

Sun, Y., C. Wang \& J. Chen. 2008. Growth inhibition of the eight species of microalgae by growth inhibitor from the culture of Isochrysis galbana and its isolation and identification. J. Appl. Phycol. 20: 315-321.

Theilacker, G. \& M. McMaster. 1971. Mass culture of the rotifer Brachionus plicatilis and its evaluation as food larval anchovies. Mar. Biol. 10: 183-188.
Tremblay, R., S. Cartier, P. Miner, F. Pernet, C. Quere, J. Moal, M. Muzellec, M. Mazuret \& J. Samain. 2007. Effect of Rhodomonas salina addition to standard hatchery diet during the early ontogeny of the scallop Pecten maximus. Aquaculture 262: 410-418.

Tzovenis, I., G. Triantaphyllidis, X. Naihong, E. Chatzinikolaou, K. Papadopoulou, G. Xouri \& T. Tafas. 2004. Cryopreservation of marine microalgae and potencial toxicity of cryoprotectants to the primary steps of the aquacultural food chain. Aquaculture 230: 457-473.

Whyte, J., N. Boume \& C. Hodgson. 1989. Influence of algal diets on biochemical composition and energy reserves in Patinopecten yessoensis (Jay) larvae. Aquaculture 78: 333-347.

Yúfera, M. \& N. Navarro. 1995. Population growth dynamics of the rotifer Brachionus plicatilis cultured in non-limiting food condition. Hydrobiologia 313/314: 399-405.

Zar, J. 1984. Biostatistical analysis. Prentice Hall, Englewoods Cliff, Nueva Jersey, EEUU.

Zhukova, N. \& N. Aizdaicher. 1995. Fatty acid composition of 15 species of marine microalgae. Phytochemistry 39: 351-356. 
